\title{
THE IMPACT OF BARK CONTENT IN WOOD PELLETS ON EMISSION PRODUCTION DURING COMBUSTION IN SMALL HEAT SOURCE
}

The combustion of biomass is relatively complicated. To minimize the emission production it is necessary to ensure the optimal setting of combustion process. The article deals with the impact of bark content in wood biomass on performance and emission parameters of a small heat source. The increasing content of bark in wood biomass changes its chemical composition and parameters, namely its net calorific value, ash content, ash fusion temperature and others. During experiments samples of wood pellets made from spruce having 1, 2, 5 and 10 percent bark content together with a reference sample without any bark content were burned. The samples were burned in a hot water boiler with a rated output of $18 \mathrm{~kW}$. It was found out that with the increasing bark content, the thermal output of the heat source decreases and the emission production increases, particularly the production of both carbon monoxide (CO) and particulate matter (PM). At the same time it was confirmed that with the increasing bark content the amount of ash also increases. Results showed that the burning of wood pellets with higher bark content has a more negative impact on the environment.

Keywords: Wood biomass, bark, emissions, particulate matter.

\section{Introduction}

The use of biomass for home heating occupies a sustainable position [1 - 2]. Biofuel in the form of wood pellets is used also in small heat sources [3]. Due to the fact that there are not only pellets made from pure wood but also pellets with bark content, it is necessary to pay attention to the impact of bark on fuel combustion characteristics (performance, net calorific value) [ 1 , 4 - 5]. Bark content in pellets influences also the fuel quality. It has impact on such parameters as moisture content, ash content, ash fusion temperature, produced emissions and particulate matter (PM). High moisture results in biofuel lower net caloric value and its incomplete combustion in the combustion appliance [2, 6 - 7]. High content of bark, which is frequently a component of burned pellets, results in more frequent maintenance of heat sources as bark contains more ash than bark less wood [8 - 10]. Increased ash content also generates higher amount of particulate matter [6 and 11], which belongs to the most harmful emissions [12]. Emissions are pollutants from biomass combustion discharged into the atmosphere. The basic emissions are carbon monoxide (CO), nitrogen oxides ( $\mathrm{NOx})$, sulphur dioxide $\left(\mathrm{SO}_{2}\right)$ unburned products known as organic hydrocarbons (OGC) and particulate matter (PM). Particulate matter discharged from local heat sources in combination with the weather has recently repeatedly led to smog situations having adverse impact on health and living conditions of people in a particular region.

The article deals with the impact of bark content in wood biomass on performance and emission parameters of a small heat source.

\section{Material and methodology}

In the framework of experimental activities we tested parameters of spruce wood pellets with bark content. Samples were produced on an experimental device for biofuel pelleting in the premises of the University of Zilina. Four samples having 1, 2, 5 and 10 percent bark contents and one reference sample without any bar content were experimentally produced. Wood pellet samples with bark content were produced in compliance with recommendations from other published materials [13 - 14].

\footnotetext{
* ${ }^{1}$ Michal Holubcik, ${ }^{1}$ Jozef Jandacka, ${ }^{1}$ Matej Palacka, ${ }^{1}$ Nikola Kantova, ${ }^{2}$ Ewa Jachniak, ${ }^{3}$ Petr Pavlik

${ }^{1}$ Department of Power Engineering, Faculty of Mechanical Engineering, University of Zilina, Slovakia

${ }^{2}$ Institute of Engineering and Environmental Protection, University of Bielsko-Biala, Poland

${ }^{3}$ Department of Energy Engineering, Faculty of Mechanical Engineering, VSB - Technical University Ostrava, Czech Republic

E-mail: michal.holubcik@fstroj.uniza.sk
} 
Following parameters were observed on the pellet samples with bark content:

- density,

- moisture,

- gross calorific value and net calorific value,

- ash content,

- ash fusion temperature,

- heat power,

- emission production and PM production.

Density of tested samples was determined in compliance with the standard STN 490108 [15] in wet conditions. Density of fuel wood chips and their individual components was calculated from the measured sample mass and its volume according to the relation:

$\rho_{0}=\frac{m_{0}}{V_{0}}\left[\mathrm{~kg} \cdot \mathrm{m}^{-3}\right]$

where: $\quad \mathrm{m}_{0}$ - the mass of a wet sample $[\mathrm{kg}]$,

$\mathrm{V}_{0}$ - the volume of a wet sample $\left[\mathrm{m}^{3}\right]$.

Moisture content was determined in compliance with the standard STN EN 14774 [16] as well as in compliance with results published in other materials [ 3 and 7]. An empty aluminum dish was weighed with a precision of $0.001 \mathrm{~g}$, the pellet samples were equally distributed on the dish surface so that $1 \mathrm{~g}$ of the sample could cover approximately $1 \mathrm{~cm}^{2}$ of the surface. The filled dish was weighed with a precision of $1 \mathrm{mg}$. The sample with the dish was consequently dried at a temperature of $105{ }^{\circ} \mathrm{C} \pm 2{ }^{\circ} \mathrm{C}$ until constant mass was achieved (the change in mass did not exceed $0.2 \%$ from the total mass loss during the following heating period - 60 minutes). The samples were dried in a weighing instrument RADWAG $50 \mathrm{SX}$. The sample resultant moisture as a mass percentage is determined from the equation:

$M_{a r}=\frac{\left(m_{2}-m_{3}\right)+m_{4}}{\left(m_{2}-m_{1}\right)+m_{4}} \cdot 100[\%]$

where:

$\mathrm{m}_{1}$ - the mass of an empty drying dish $[\mathrm{g}]$,

$\mathrm{m}_{2}$ - the mass of a drying dish and sample before drying [g],

$\mathrm{m}_{3}$ - the mass of a drying dish and sample after drying [g]

$\mathrm{m}_{4}$ - the mass of moisture connected with the container [g].

Gross calorific value of pellet samples was determined in compliance with the standard STN EN 14918 [17] with the use of a calorimeter LECO AC 500.

Net calorific value was determined from gross calorific value on the basis of the relation:

$Q_{i}=Q_{s}-2.453 \cdot\left(M_{a r}+9 H_{2}\right)\left[M J \cdot k g^{-1}\right]$

where: $\quad Q_{S}-$ gross calorific value of the fuel $\left[\mathrm{MJ} \mathrm{kg}^{-1}\right]$,
$\mathrm{M}_{\mathrm{ar}}$ - relative fuel moisture in $\left[\mathrm{kg} \cdot \mathrm{kg}^{-1}\right]$,

$\mathrm{H}_{2}$ - hydrogen content in fuel $\left[\mathrm{kg} \cdot \mathrm{kg}^{-1}\right]$.

Ash content of the prepared pellet samples was determined in compliance with the standard STN EN 18122 [18], used for determining ash content of solid biofuels and at which the maximum temperature of $550{ }^{\circ} \mathrm{C}$ is achieved in a muffle furnace and in compliance with the standard STN ISO 1171 [19], used for determining ash content of solid fuels and at which the maximum temperature of $815^{\circ} \mathrm{C}$ is achieved in a muffle furnace. Ash content was determined from the equation:

$A_{d}=\frac{\left(m_{3}-m_{1}\right)}{\left(m_{2}-m_{1}\right)} \cdot 100[\%]$

where $m_{1}$ - the mass of an empty dish $[\mathrm{g}]$,

$\mathrm{m}_{2}$ - the mass of a dish with a test piece [g],

$\mathrm{m}_{3}$ - the mass of a dish with ash $[\mathrm{g}]$.

Determination of ash fusion temperature was done in compliance with the standard STN ISO 540 [20]. Ash is spread in an agate dish so that the maximum grain size will be less than 0.063 millimeter. The required amount of crushed ash is moisturized with distilled water to form a smooth paste which is pressed into a mold to shape a test ash piece. The mold can be greased with a thin layer of vaseline to get the ash piece out more easily. Then the ash piece is fixed to a pad. The ash piece should have sharp edges. If the piece is damaged, it has to be excluded from measurement. The test pieces prepared this way are put into a measuring device LECO AF 700 (Fig. 1).

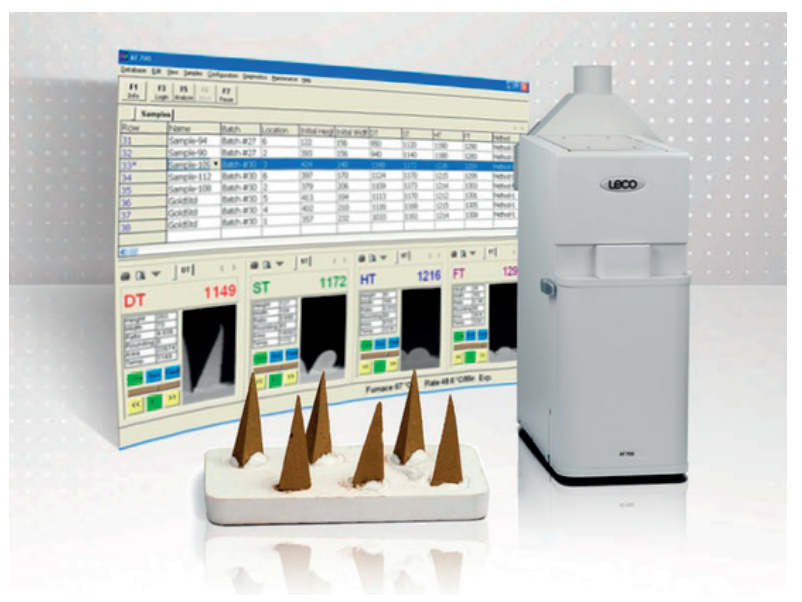

Fig. 1 Measuring device LECO AF 700

In compliance with the standard STN ISO 540 [8] following characteristic melting temperatures were recorded within individual phases of measurement:

- deformation temperature "DT" - the temperature where first changes in the shape of either a test piece tip or edges occur due to melting, 
- sphere temperature "ST" - the temperature where the edges of a test piece are rounded due to smelting,

- hemisphere temperature "HT" - the temperature where the test piece takes on a hemisphere shape, or in other words, the height equals to half of the base average,

- flow temperature "FT" - the temperature where ash flows across the plate in a layer whose height represents one third of the height of the test piece at a hemisphere temperature.

Each experiment and consequent calculation was performed at least three times for each sample and the result is an arithmetic average of the measurements.

The combustion took place in a small heat source USPOR 18 AUTOMAT with a rated heat output of $18 \mathrm{~kW}$ which was tested on an experimental device designed for the measuring of heat output and emission production. The connection of an automatic heat source to the experimental device can be seen in Fig. 2. The device is built from an experimental boiler, a heat consumption device (i.e. device for regulation of heat produced by the boiler), a gaseous emission analyzer, a particulate matter analyzer, measuring apparatus to which all measuring instruments are connected and a computer for the processing of measured data. Various parameters are recorded every $20 \mathrm{~s}$. During the measurements constant chimney draft $12 \pm 2 \mathrm{~Pa}$ via a flue fan is ensured. Its speed is controlled by a frequency regulator. All pellet samples with various bark content were burned at the same operating settings of the boiler - fuel feeding time of a spiral conveyor is $18 \mathrm{~s}$, idle time of the conveyor is $25 \mathrm{~s}$, the combustion air is set to constant air access.

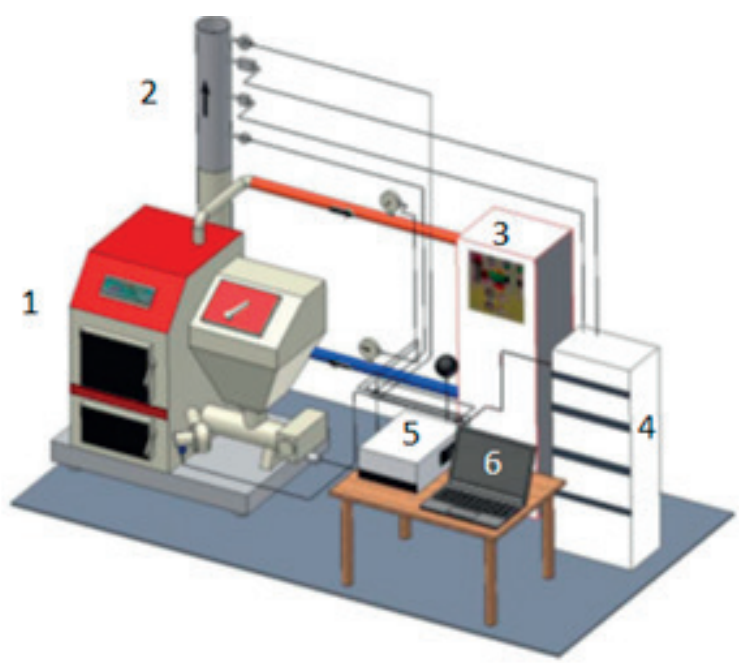

Fig. 2 Connection of the automatic heat source (1 - heat source,

2 - flue gas measuring section, 3 - emissions analyzer, 4 - temperature controller, 5 - logger, 6 - PC)

The thermal power of an experimental boiler was measured by calorimetric method where the flow of the heat transfer medium (water) was measured by a magnetic flow meter YOKOGAWA
ADMAG AXF with an accuracy of $\pm 0.35 \%$. The temperature difference of the heat transfer medium (water) was measured by two paired resistance thermometers PT100 with a measurement accuracy $\pm 0.4 \%$.

The concentrations of $\mathrm{O}_{2}, \mathrm{CO}_{2}, \mathrm{CO}$, NOx in flue gases were measured by a flue gas analyzer ABB AO 2020, which recorded the emission values in ppm units (parts per million). These values were converted to $\mathrm{mg} . \mathrm{m}^{-3}$ according to the equation:

$Y=X \cdot \frac{M}{22.41} \cdot \frac{p}{101325}$

where $\mathrm{Y}$ represents a calculated production for one of the emissions in $\mathrm{mg} \cdot \mathrm{m}^{-3}, \mathrm{X}$ is the measured emission in ppm unit, $\mathrm{M}$

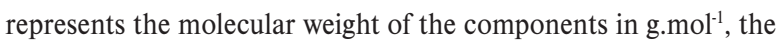
value 22.41 represents the standard molar volume in $\mathrm{dm}^{3} \cdot \mathrm{mol}^{-1}$ and $\mathrm{p}$ represents the pressure in $\mathrm{Pa}$. The normalized concentration of oxygen in the flue gas from a boiler $\mathrm{O}_{2 \mathrm{n}}$ is considered to be $10 \%$. Therefore, the measured values of each emission are recalculated according to the formula:

$Y_{\left(10 \% Q_{2}\right)}=Y \cdot \frac{21-Q_{2 n}}{21-Q_{2 a v g}}$

where $\mathrm{Y}_{(10 \% 02)}$ is the normalized emission concentration in mg. $\mathrm{m}^{-3}$, $\mathrm{Y}$ represents emission, which is calculated by a previous equation (Eq. 5) in mg. $\mathrm{m}^{-3}, \mathrm{O}_{2 \mathrm{n}}$ represents the normalized concentration of oxygen in the flue gas in $\%$ and $\mathrm{O}_{2 \text { avg }}$ represents the mean value of the oxygen concentration in the flue gas in \%. This measuring device is regularly calibrated by an authorized specialist from an external company.

Particulate matter measurement was conducted by gravimetric method. Gravimetric method is given by the standard ISO 9096. It is a manual, single-use method where samples are taken by a probe from flowing gas. This method gives an average value of PM for a given span of time within which a partial flow from an exhaust gas sample is taken. Exhaust gases are guided through filtration or sediment systems which catch either all particles or only those of pre-defined size. Filtration materials are weighed before and after measurements and final mass concentration is calculated from a sample volume. Sampling probes can be placed either directly into hot flow of exhaust gases or outside the flow (these systems must be heated to avoid condensation or nucleation). Solid particles are collected from flowing gas with the help of the probe. From them an average concentration of flowing gas particles is determined. Exhaust gases were taken from a chimney duct with the help of a three-stage separation impactor (Fig. 3). The sampling was conducted at the same speed of exhaust gas flow as in the pipe. Hot gas was led from the pipe through cooling and drying equipment up to the sampling unit. In the cooling equipment exhaust gases were cooled and water vapor was removed from the exhaust gas sample. In the silica gel-water absorption tower residual moisture of exhaust gases was removed. 

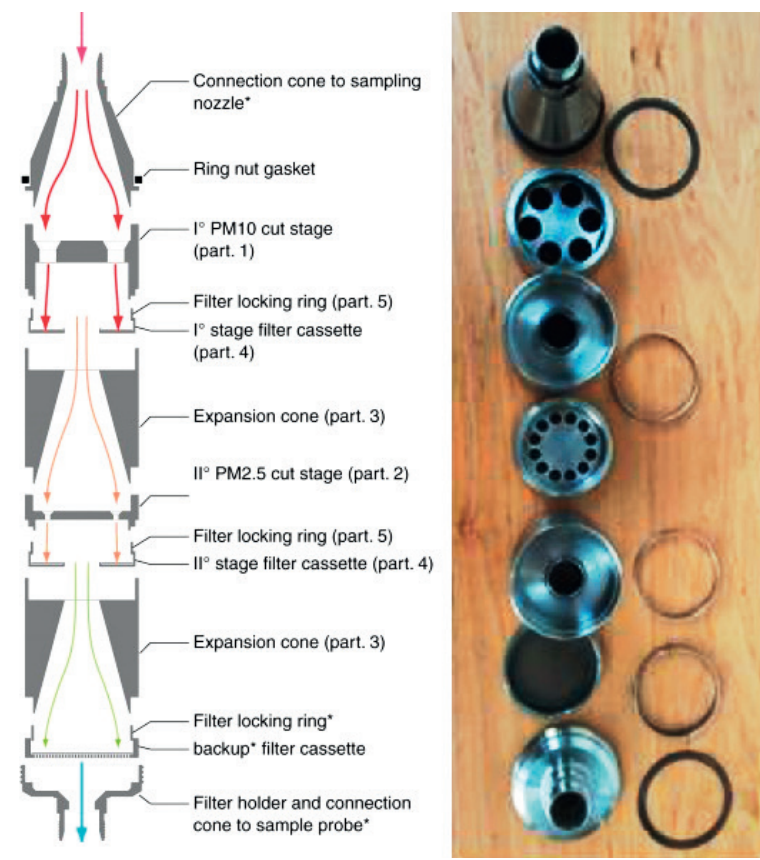

Fig. 3 Three-stage separation impactor

\section{Measurement results}

Experimentally determined density values of pellet samples with bark content can be seen in Fig. 4 (left). Figure 4 (right) shows measured density of samples. The graphs clearly show that with the increasing bark content in pellets both density and moisture of samples increase.

Figure 5 (left) shows a graph of experimental measurements of gross calorific value and calorific value. The net calorific value of wood pellets with zero bark content is $17.12{\mathrm{MJ} . \mathrm{kg}^{-1}}^{-1}$ and the calorific value of pellets containing ten percent bark is

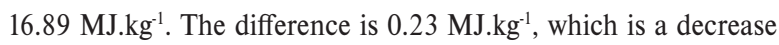
approximately by $1.35 \%$. Output of the boiler taken during the

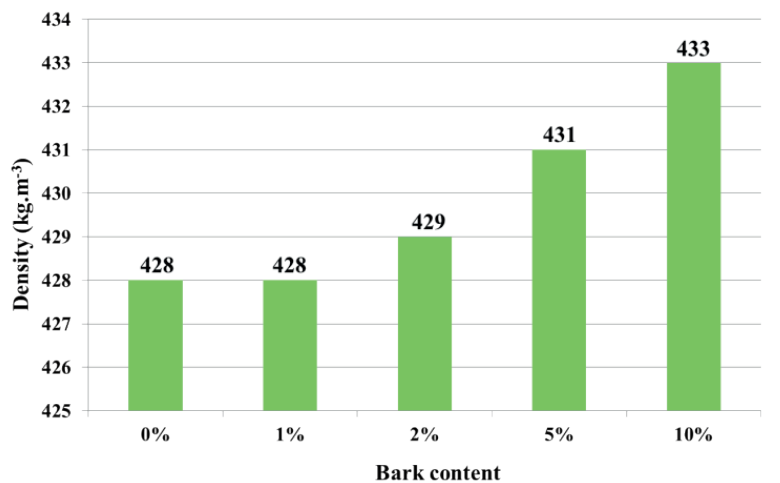

combustion of pellet samples can be seen in Fig. 5 (right). As expected from determination of net calorific value, the boiler output decreases with the increase of bark content. An exception is a pellet sample with one percent bark content, where the taken output was $11.81 \mathrm{~kW}$.

Resultant values of the experimental determination of ash content for individual pellet samples at the maximal temperature of $550{ }^{\circ} \mathrm{C}$ and $815{ }^{\circ} \mathrm{C}$ can be seen in the graph in Fig. 6 (left). The reference pellet sample with zero bark content tested at temperature of $550{ }^{\circ} \mathrm{C}$ contained by $0.071 \%$ more ash than the sample tested at temperature of $815{ }^{\circ} \mathrm{C}$. The wood pellet sample with ten percent bark content tested at temperature of $550{ }^{\circ} \mathrm{C}$ contained by $0.78 \%$ more ash than the sample tested at temperature of $815{ }^{\circ} \mathrm{C}$. The graph clearly shows that with the increasing bark content, ash content of pellets also increased approximately by $12.4 \%$ at testing temperature of $550{ }^{\circ} \mathrm{C}$ and approximately by $13.1 \%$ at temperature of $815{ }^{\circ} \mathrm{C}$.

Experimentally taken results determining the ash fusion of pellet samples with different bark content are in Fig. 6 (right). From the graph it is obvious that deformation temperatures of pellets with zero bark content are higher than those having ten percent bark content.

The graph in Fig. 7 (left) shows experimentally measured content of $\mathrm{O}_{2}$ and $\mathrm{CO}_{2}$. The highest $\mathrm{O}_{2}$ concentration was taken in a pellet sample with ten percent bark content and the lowest concentration was recorded for a sample with zero bark content. The difference is $0.32 \%$, which is the increase by $2.1 \%$. On the contrary, the lowest $\mathrm{CO}_{2}$ concentration was recorded for pellet samples with ten percent bark content $-5.138 \%$ and the highest concentration was measured in pellet sample with one percent bark content $-5.487 \%$.

Average values of carbon monoxide $(\mathrm{CO})$ production taken during combustion can be seen in Fig. 7 (right). $\mathrm{CO}$ is a by-product of incomplete combustion and its amount depends on the amount of oxygen supplied to combustion. The lowest CO production was recorded for pellet samples having one percent bark content. The lower $\mathrm{CO}$ production in pellets could be caused

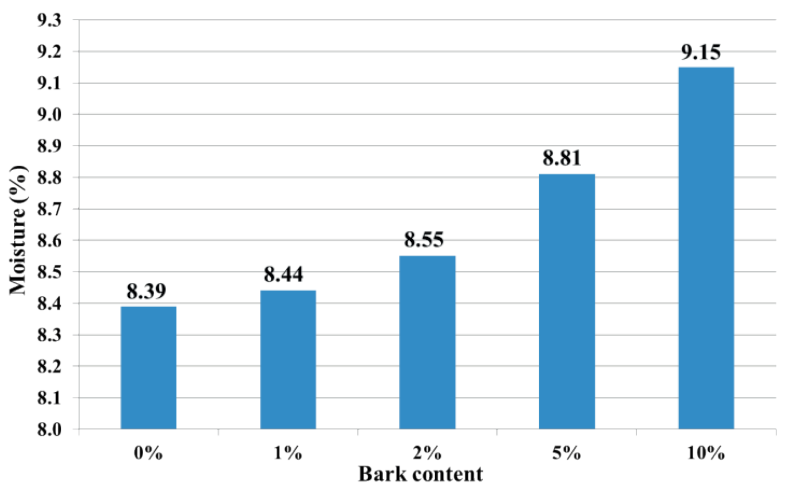

Fig. 4 Density of pellets (left) and moisture of pellets (right) 

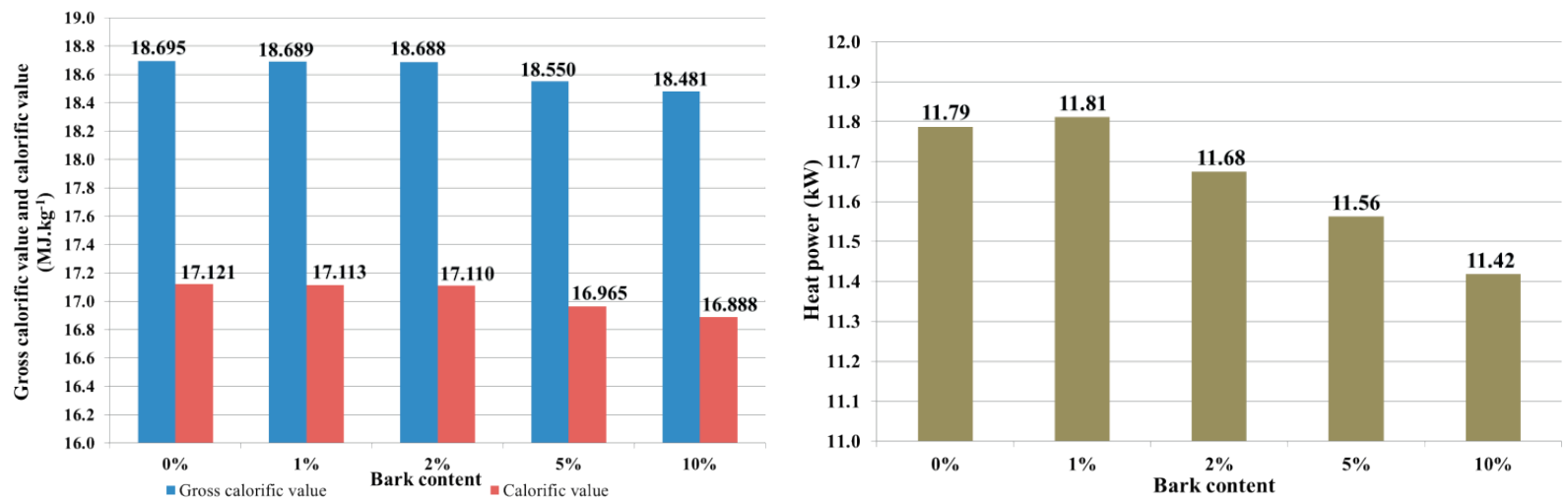

Fig. 5 Gross and net calorific values (left) and achieved output of the boiler (right)

by impaired oxygen supply. The emission limit for $\mathrm{CO}$ combustion is stricter than other limits due to the fact that hydrocarbon emissions are, to a great extent, carcinogenic. According to the standard STN EN 303-5 [21], the boiler with automatic fuel supply whose output is up to $50 \mathrm{~kW}$, which was used for the experiment, belongs to energy efficiency class $\mathrm{V}$. The standard specifies the maximum level of $\mathrm{CO}$ for the respective boiler $500 \mathrm{mg} . \mathrm{m}^{-3}$. From the figure it can be seen that the pellet samples do not meet the limit.
The amount of nitrogen oxides (NOx) depends on the flame temperature at which oxidation takes place, on fuel characteristics and combustion speed. Nitrogen oxides are significant air pollutants. The recorded amounts are presented in Fig. 7 (right). The highest content of NOx was recorded in samples having ten percent bark content; the concentration was $130 \mathrm{mg} \cdot \mathrm{m}^{-3}$. The concentration ranging from 47 to $140 \mathrm{mg} \cdot \mathrm{m}^{-3}$ can cause pneumonia and the concentration from 560 up to $940 \mathrm{mg} \cdot \mathrm{m}^{-3}$ is a lethal dose causing pulmonary edema.
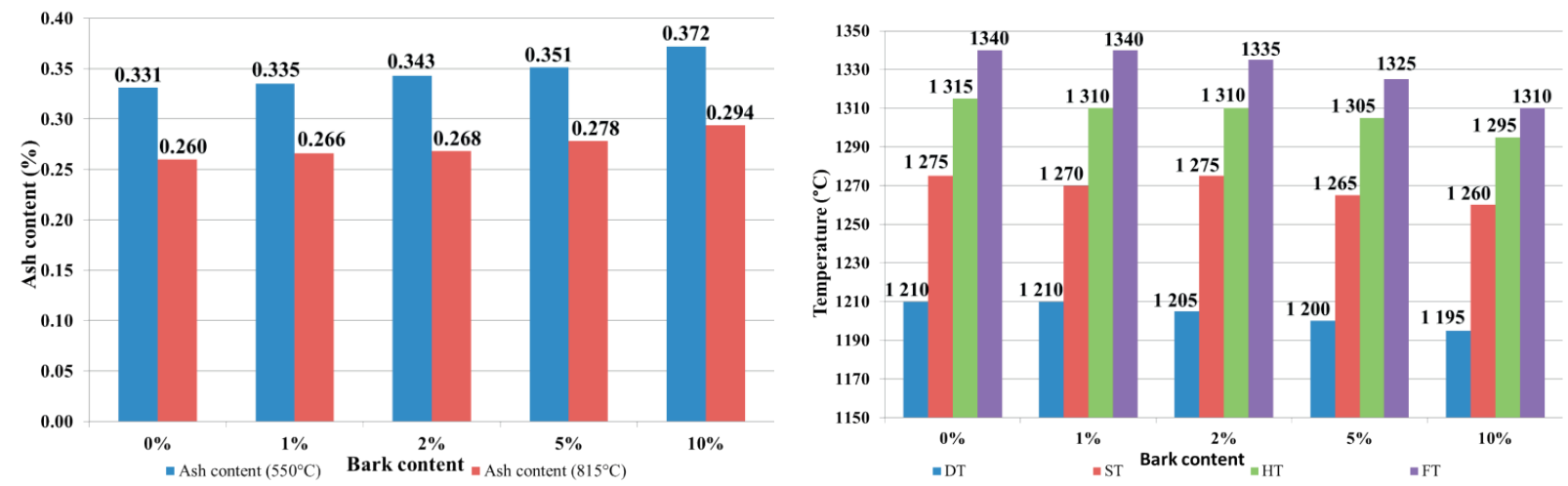

Fig. 6 Ash content (left) and ash fusion temperature (right)
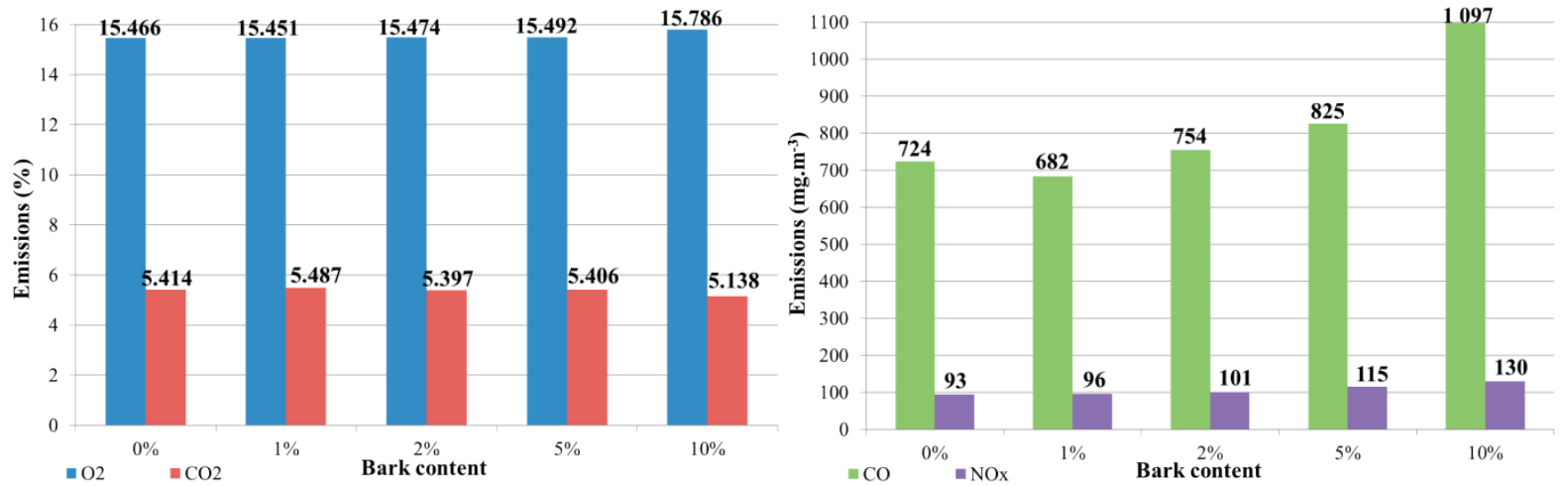

Fig. 7 Emission production during sample combustion 


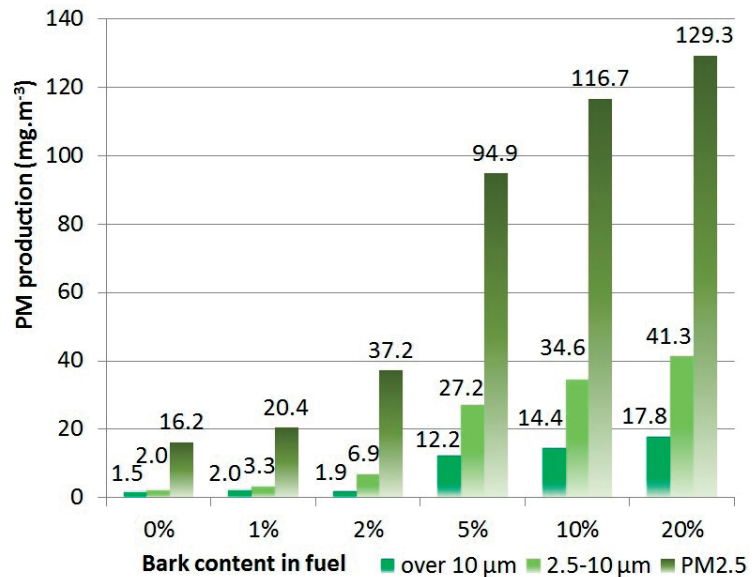

Fig. 8 PM production during sample combustion

The graph in Fig. 8 shows an amount of particulate matter caught in the filters during measurements. The figure compares particulate matter concentrations caught during combustion of experimental samples of wood pellets with different bark content. It is obvious that the highest amount of particulate matter was caught in pellet samples having ten percent bar content. The recorded concentrations in the mentioned samples having a particle size more than $10 \mu \mathrm{m}$ were higher by $36.3 \mathrm{mg} \cdot \mathrm{m}^{-3}$, those having a size $2.5-10 \mu \mathrm{m}$ were higher by $32.6 \mathrm{mg} \cdot \mathrm{m}^{-3}$ and particles having a size PM2.5 were higher by $100.5 \mathrm{mg} \cdot \mathrm{m}^{-3}$ in comparison with the reference pellet sample (pellets having zero bark content).

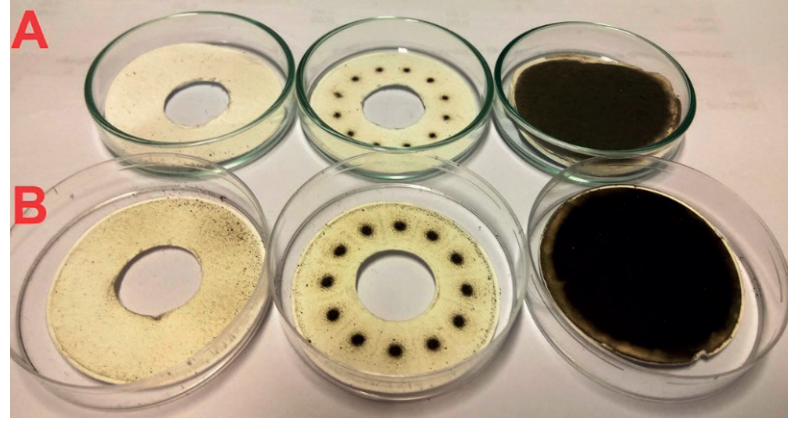

Fig. 9 Filters collecting PM with a three stage separation impactor
Glass fiber filters without organic binders with retention efficiency above $95 \%$ were used to collect PM by a gravimetric method. Figure 9 shows filters after exhaust gas samples were collected by a separation impactor. Filters "A" were taken after the burning of pellet samples without any bark. Filters "B" taken after the burning of pellet samples having ten percent bark content can be seen in Fig. 9. Particles greater than $10 \mu \mathrm{m}$ were collected in the filter on the left while particles ranging from $2.5 \mu \mathrm{m}$ up to $10 \mu \mathrm{m}$ were collected in the filter in the middle. In the filter on the right are particles having a size below $2.5 \mu \mathrm{m}$ (so called PM2.5).

\section{Conclusion}

Based on the achieved results we can conclude that bark content in pellets has a significant impact not only on performance but also on environmental characteristics of pellets. Higher bark content in pellets increases ash content, which can adversely influence combustion process, mainly due to higher ash production during combustion and consequent necessity of more frequent boiler cleaning. More serious shortcoming is the fact that with higher bark content, ash fusion temperature decreases. Lower ash fusion temperature can cause some problems within combustion process, for example, to lower heat transfer intensity in heat exchangers, to cause corrosion of combustion equipment, to prevent fuel and combustion air supplies, etc. But wood bark has relatively high net calorific value; therefore, its potential can be energetically used. Attention should be paid to its negative impact on the environment due to higher concentrations of $\mathrm{CO}$, NOx and PM as mentioned in this article.

\section{Acknowledgement}

This work was supported by the projects VEGA 1/0548/15 "The impact of bark content and additives on mechanical, energy and environmental characteristics of wood pellets" and APVV-150790 "Optimization of biomass combustion with low ash melting temperature”.

\section{References}

[1] SOOS L., KOLEJAK M., URBAN F.: Biomass - A Renewable Source of Energy (in Slovak). Vert: Bratislava, 2012.

[2] JANDACKA, J., MALCHO, M., MIKULIK, M.: Biomass as a Source of Energy (in Slovak). Zilina: Publishing house GEORG, 2007, 241.

[3] DZURENDA, L., PNAKOVIC, L.: Energy Characteristic of Biofuel - Leaves Falling Down from Hardwood Trees in Autumn (in Slovak). Acta Facultatis Xylologiae Zvolen, 57, 1, 2015, 119-126.

[4] DURICA, P., BADUROVA, S., PONECHAL, R.: Energy and Environmental Evaluation of the Selected Wooden Family Houses. Communications - Scientific Letters of the University of Zilina, vol. 15, No. 1, 2013, 88-95. 
[5] RACKO, V., CUNDERLIK, I.: Width, Content and Basic Physical Characteristics of Beech Bark on a Mix Offered for Production of Paper and Cellulose (in Slovak). Selected Processes at the Wood Processing, 2011, 65-73.

[6] CARnOGURSKA, M., PRIHODA, M., KOSKO, M., PYSZKO, R.: Verification of Pollutant Creation Model at Dendromass Combustion. J. of Mechanical Science and Technology, vol. 26, No. 12, 2012, 4161-4169.

[7] DZURENDA, L., PNAKOVIC, L.: Quantification of the Ash Content from Biofuel - Wood According to ISO 1171 (2003) and EN 14775 (2010). Annals of Warsaw University of Life Sciences, No. 86, 2014.

[8] FILBAKK, T., JIRJIS, R., NURMI, J., HOIBO, O.: The Effect of Bark Content on Quality Parameters of Scots Pine (Pinus sylvestris L.) Pellets. Biomass and Bioenergy, 35, 2011, 3342-3349.

[9] LONGAUER, J., LUPTAK, O., KOSKA, P.: Gross Calorific Value and Net Calorific Value of Wood Waste (in Slovak), VPA 5/1987, Zvolen, 1988, 61.

[10] VIGLASKY, J.: Biomass Potential in the Region and its Accessibility for Power Engineering (in Slovak). Plynar. Vodar. Kurenar + Klimatizacia, vol. 10, No. 3, 2012, 38-42.

[11] VITAZEK I., J. TIROL: Emissions from Biomass Combustion (in Slovak). Technika v technologiach agrosektora 2009, Slovenska polnohospodarska univerzita: Nitra, 2009, 73-79.

[12] KAPJOR, A., HUZVAR, J., FTOREK, B., VANTUCH, M.: Criterion Equations of Heat Transfer for "n“ Horizontal Pipes One Above Another at Natural Convection in Linear Method of Approximation, Communications - Scientific Letters of the University of Zilina, vol. 16, No. 3A, 2014, 54-61.

[13] MELIN, S.: Bark as Feedstock for Production of Wood Pellets. Wood Pellet Association of Canada, 2008, 42.

[14] SUADICANI, K., GAMBORG, C.: Fuel Quality of Whole-Tree Chips from Freshly Felled and Summer Dried Norway Spruce on a Poor Sandy Soil and a Rich Loamy Soil. Biomass and Bioenergy, 17, 1999, 199-208.

[15] STN 49 0108, 1993: Wood - Density Determination.

[16] STN EN 14774, 2009: Solid Biofuels. Determination of moisture content. Oven dry method. Part 1: Total moisture. Reference method.

[17] STN EN 14918, 2009: Solid Biofuels. Determination of net calorific value.

[18] STN EN ISO 18122, 2016: Solid Biofuels. Determination of ash content.

[19] STN ISO 1171, 2003: Solid Fuels - determination of ash.

[20] STN ISO 540, 2010: Hard Coal and Coke. Determination of ash fusion.

[21] STN EN 303-5, 2012: Heating Boilers. Part 5: Heating boilers for solid fuels, manually and automatically stoked, nominal heat output of up to $500 \mathrm{~kW}$. Terminology, requirements, testing and marking. 